\title{
Economic viability of eCare solutions
}

\author{
J. Van Ooteghem, A. Ackaert, S. Verbrugge, D. Colle, M Pickavet, P. Demeester
}

Ghent University - IBBT, Dept. of Information Technology (INTEC),

G. Crommenlaan 8 bus 201, 9050 Gent, Belgium

tel: +3293314900, fax: +3293314899

\{jan.vanooteghem, et al. $\}$ @intec.ugent.be

\begin{abstract}
Provisioning of good quality care to the elderly population and at the same time reducing the pressure on the health care expenditures is a challenging issue for governments today. Many ICT supported, distant care systems (eCare) have been proposed but few have found their way to the market. The problem is to provide a viable business case for each actor involved (including eCare platform, health care and finance providers) when offering eCare services. We have constructed a model for evaluating the (socio-)economic viability of different business models when introducing eCare solutions. A multi-actor approach has been implemented, calculating and evaluating the business case for each actor involved. For a Belgian case we will show (socio)-economic advantages to participate in an eCare ecosystem.
\end{abstract}

Keywords: eCare, Business model, Multi-actor analysis, Economic viability

\section{Introduction}

The increasing elderly population in most OECD (Organisation for Economic Cooperation and Development) countries, particularly those in the EU and Japan, will lead to many challenges in the upcoming years. Providing good quality care, to more elderly people, with a lower availability of professional care providers and within a stringent health care budget calls for innovative solutions. Within this paper we focus on eCare solutions and services in view of the care provisioning to elderly people.

For several years many initiatives have been taken to explore the technical and social implications of a wide variety of such eCare schemes. Several companies or consortia have started commercial services but large-scale rollouts have been lacking due to the absence of convincing business models. The regulatory framework is not always adapted for offering eCare services which leads to postponing the introduction of these innovative services. A report by the European Commission presents an overview of business models for eHealth [1] but is not focused on independent living scenarios. The number of published value network models to evaluate the economic feasibility of eCare services is limited. A literature study has been executed. Publicly available studies on realizations and trials, stakeholder readiness analysis [2] as well as a review of guidelines [3] and key indicators [4] for cost-benefit analysis [5] for telehomecare can be found, but are rare. 
The work presented in this paper is part of the IBBT TranseCare project [6], a research project aimed at developing ICT support tools and services for an eCare platform. It encompasses diverse research fields including social, technical, economic and legal contexts. A custom configurable eCare platform has been developed within the project that connects to the users' television through the Internet, and allows for video-telephony with a professional care help-desk, other users of the eCare system and informal caregivers using an instant messaging client on their PC. Within this paper, we extend the services offered with eConsultations and telemetry functionality.

Within the IBBT TranseCare project a value network evaluation model of the envisaged eCare platform has been elaborated, able to calculate and analyze the (socio-)economic viability of eCare business models. A multi-actor analysis indicates the benefits for all actors involved in the eCare ecosystem. This model will help formulating a business case towards governmental agencies, insurance companies, health care providers or private investors as to how much and how soon to invest in eCare. This model is based on previous work presented in [7] and [8].

The paper first introduces the generic business roles, indicating for each role (eCare platform, health care and finance provider) the different parameters taken into account. Next we present a realistic business model for the Belgian situation. The economic viability results for each actor, based on the multi-actor analysis, are shown. Finally we end this paper with some considerations, conclusions and future work.

\section{Business roles}

We start by identifying the different business roles which need to be executed when offering eCare services. All roles within the eCare ecosystem can be categorized into three larger types of providers. The eCare platform providers build, maintain, distribute, operate and connect the system; health care providers supply patient's care; finance providers fund the eCare system. The different providers (Fig. 1) will be discussed in more detail in the next paragraphs.
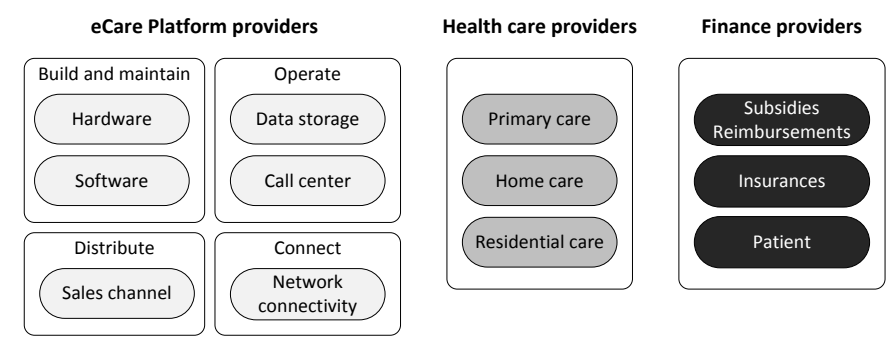

Fig. 1: Providers within the eCare ecosystem

\section{eCare platform providers}

An eCare platform will be developed, which includes costs for development, production and maintenance. The hardware provider will have to develop the eCare 
home device which is a large upfront cost, next to the production costs. Also hardware for measuring telemetry data from patients (e.g. blood pressure) needs to be foreseen. Next to these infrastructure costs, operational costs such as maintenance and repair have to be taken into account.

Next to the hardware, software needs to be developed, which also requires a large upfront investment. We opt for a license fee per eCare home device for regaining the implementation and operational costs (e.g. helpdesk).

A distribution channel provider will take care of the distribution, marketing, sales and billing processes and are calculated as percentage of the total infrastructure costs.

The call center provider takes care of emergency and helpdesk calls. The costs are calculated based on the amount of employees required to take all calls plus an overhead cost. An estimation of the amount of call minutes per patient is required.

The data center provider will take care of storage and security of the patient's telemetry data. The costs include a large upfront setup cost. We opt for a one-off license fee for regaining the investment and a yearly subscription fee per patient for covering the operational costs.

In this model we consider the home network connectivity to be foreseen by the patient. As the service focuses on the elderly population, a market segment that is closely related to the digital divide issue, a social subscription fee (with limited bandwidth) has taken into account. If other services (e.g. IPTV, Internet) could make use of this network connection, this cost should be excluded (sunk cost).

\section{Health care providers}

The introduction of eCare services such as telemetry monitoring will lead to a change of type and number of consultations with a primary care provider (in this paper focused on general practitioners (GP)). Patients can be monitored through their telemetry data updates to the database, which GPs can consult. A video link could be set up to the patient when required. These optimizations are calculated based on the time saved for the GP. Following assumptions were considered:

- Decrease in practice and home consultations: some consultations will be redundant thanks to eCare solutions.

- eConsultations: replacement of the former practice and home consultations by video link communication, which leads to time savings for the GP and patient.

For home care, the same reasoning could be set up as for the GP. Patients requiring help for activities of daily living including taking medicines or telemetry measurements could take advantage of an eCare platform and according services. This will lead to optimizations for home care organizations (in terms of time savings, man power, work pressure, etc). Following assumptions were considered:

- Decrease in number of visits: consultations solely for monitoring telemetry measurements could be shifted to the use of eCare services.

- Decrease in time per visit: help could be better organized e.g. patient could perform their own telemetry measurements, improved contact with home care personnel (text messages or video), etc.

- Provision of distant care for certain items: a "good morning" service could be deployed, offering a daily contact moment to check on the elderly person. 
Elderly people demanding residential care are often put on a waiting list due to scarcity of capacity. The total size of this problem is hard to measure (no real data can be found). Government has recognized this problem, but it requires investments in new retirement homes, which takes a long time to execute. The introduction of eCare services could be a solution to bring transmural care to 'potential future' residents. Currently high caring patients dominate the resident population due to the scarcity in capacity leading to an unequal mix between low and high caring patients. We calculated the total unserved needs for intramural care of the elderly population. The offering of transmural (eCare) services will result in a decrease of unserved needs and thus in a better health care system.

\section{Finance providers}

The most important finance role provides subsidies and reimbursements for eCare solutions, a role taken up normally by the government. The amount of subsidies will be large, but socio-economic benefits need to be considered. Other roles could include financial support of voluntary aid or reimbursements of GP eConsultations.

When patients make use of the eCare system, public or private insurance providers will benefit by having a better track record of their customers, leading to a better assessment of the patient and potentially a lower tariff. When offering eCare services, this could be an opportunity to attract new or retain current customers.

The main issues concerning the migration towards eCare services for the patients relate to the trade-off between their own financial contributions versus improved/additional health care they receive:

- What services will the patient accept (e.g. telemetry, communication, emergency button, etc) and which actions will the patient perform?

- Will this efficiency increase lead to a willingness to pay that is high enough for keeping the system sustainable?

- Which technical capabilities are required for the patient?

- Will the patient trust the system (security, misconduct by other parties)?

- Will this all leads to an improved health care system?

\section{Business model}

Different business models can be formulated based on the dominant role of one of the actors, taking up most of the roles. After a focus group discussion with people from within the Belgian health care sector, a "realistic model" was formulated. This model can be seen in Fig. 2. Home care actor will be the dominant actor, taking up the roles of care taking and platform distribution (intermediary role). The platform is developed by a third party developer, government is responsible for storage of patient records, an external call center handles all emergency calls, and a connectivity provider takes care of the network connection. A subsidy is foreseen by government, even as a personal financing of the operational expenses by the patient.

We assume an intermediary model is used, meaning that one actor will take care of the distribution of the system, including the billing to the patient. This requires that 
the home care provider will arrange all financial engagements with other actors, excluding the connectivity, as this will be a task for the patient.

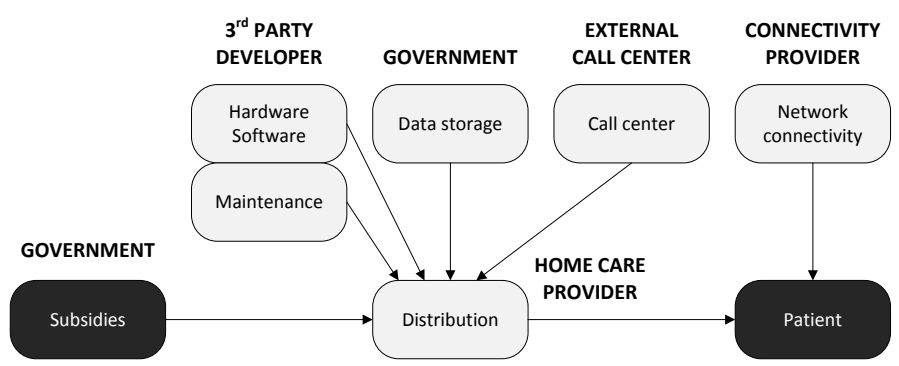

Fig. 2: Realistic Belgian business model

\section{Results}

A detailed techno-economic model was elaborated to calculate and evaluate potential business models for the introduction of eCare solutions, making use of a multi-actor approach, where the economic viability of the business case for each actor is calculated separately. Costs and benefits for the different roles are allocated to the appropriate actors, taking into account the appropriate profit margin of each actor (size depends on type of actor, public vs. private, etc). In this paper we did not focus on the techno-economic model (assumptions and calculations) itself but on the results of the business model presented in the previous section.

As precondition we assume no net loss, either in terms of financial or social value, for all current/future actors within the ecosystem when eCare services are offered, this to guarantee the probability of acceptance of the business model.

\section{Health care providers}

As described in the previous section, we assume that the number of consultations with the general practitioner would decrease due to the implementation of eCare services. We estimated a $20 \%$ decrease in revenues from patients older than 65 for the GP (of which $5.9 \%$ for in practice consultations and $14.1 \%$ for home consultations). This decrease is higher for home consultations due to a higher tariff and a replacement of home visits with eConsultations. The time gained due to the decline in consultations could be used for other purposes. First eConsultations will be a new source of revenues. The time required for an eConsultation compared to the real life consultations is smaller, so additional consultations could be planned with new patients (about $1.3 \%$ of additional revenues). The tariff for eConsultations is set to have a break-even situation for the GP (accounting in total for the other $18.7 \%$ of new revenues). This could easily be altered when the GP demands a higher profit margin (e.g. in order to recuperate time to set up the eCare system). An overview can be seen in Table 1. 
Table 1: Financial implications for the general practitioner

\begin{tabular}{|l|l|l|l|}
\hline GP revenue decrease & & GP revenue increase & \\
\hline In practice consultations & $5.9 \%$ & eConsulations & $18.7 \%$ \\
\hline Home consultations & $14.1 \%$ & Consultations by new patients & $1.3 \%$ \\
\hline
\end{tabular}

Due to a more efficient approach when eCare services are available (e.g. video communication), time for home care visits could be saved. This can either lead to a lower number of consultations per patient (e.g. when only telemetry data needs to be checked) or in a more efficient visit (e.g. better follow-up of the patient, do it yourself by the patients for measuring telemetry data or selecting services online such as menus, etc). The results can be seen in Table 2. The total amount of time savings per patient per year (less consultations and savings in time per visit) is estimated at 198 and 122 minutes, respectively. This time saved could be used to take care of new patients, or to lower work pressure in this sector.

Table 2: Home care time savings

\begin{tabular}{|l|l|}
\hline Type of visits & Time saved per year per patient \\
\hline Decrease of home care visits & $198 \mathrm{~min}$. \\
\hline More efficient home care visit & $122 \mathrm{~min}$ \\
\hline
\end{tabular}

When no additional services are offered to the elderly population, an increase in unserved needs can be detected (due to the aging of the population). Currently in retirement homes there is a shift towards patients with high care need, leading to an unequal mix between low and high caring patients. The introduction of eCare services could be a solution to bring transmural care to 'potential future' residents, and thus serving the needs of the elderly population still able to life independently. We calculated the optimization in served population (Fig. 3). After 6 years, we would again reach the level of 2009 (set as norm), even due to the aging of the population. After 10 years, a decline of unserved elderly population of about $30 \%$ can be reached, compared to the situation of no intervention, which is immense. These results could be related to the discussion of the waiting list problem.

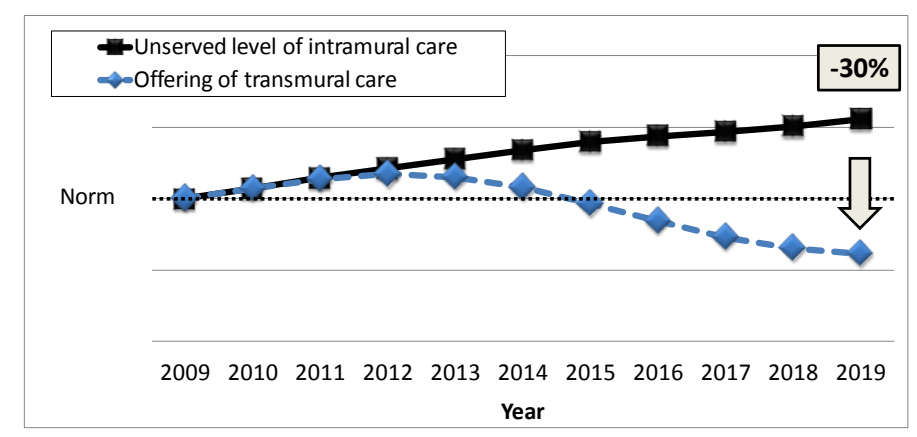

Fig. 3: Retirement homes - unserved vs. served needs 


\section{eCare platform and finance providers}

Based on the Belgian market situation, we estimated the profit margins for each actor. Third party developers, connectivity providers and external call centers are private companies, striving for high profit margins. Our health system is well built out, with health care subsidized by the government and obliged subscriptions with public insurance companies. This ensures that most of these insurance companies are non-profit organizations, resulting in low profit margins. Home care organizations depend on insurance companies and strive for (low) profit in the end. As every private or public actor determines its own profit margin, they strive for a viable business case.

In our proposed business model, the home care provider will act as intermediary company (single point of contact to the customer), thus setting up agreements with all the different actors involved. All cost (including profit margins of the different actors and its own) will be included in the final tariff paid by the patient. Table 3 shows the monthly tariff paid by the customer to the home care provider split up into the different eCare roles. The eCare infrastructure cost amounts to about $23 \%$ of the total monthly tariff and includes the eCare home device, software development and telemetry equipment. This cost could be subsidized by the government (which has been done with other similar (with less functionality) systems in Belgium). The operational cost $(14 \%)$ consists of infrastructure operations and maintenance and distribution costs. Call center $(31 \%)$ and network connectivity $(25 \%)$ are the largest costs. The first can be explained by the fact that this relates to purely personnel costs, which are very expensive. In view of the connectivity cost it is a known fact in Belgium that broadband tariffs are high compared to our neighboring countries.

The price paid by the customer for this eCare solution is comparable to the current PAS (personal alarm systems) tariffs applied in Belgium, but offers additional functionalities. Due to confidentiality reasons, we could not publish the actual tariff.

Table 3: Monthly tariff distribution

\begin{tabular}{|c|c|c|c|c|}
\hline $\begin{array}{c}\text { eCare } \\
\text { infrastructure cost }\end{array}$ & $\begin{array}{c}\text { eCare } \\
\text { operational cost }\end{array}$ & Call center & Data storage & Connectivity \\
\hline $23 \%$ & $14 \%$ & $31 \%$ & $7 \%$ & $25 \%$ \\
\hline
\end{tabular}

\section{Conclusion and future work}

In this paper we analyzed the economic viability of eCare solutions. A multi-actor analysis was executed, calculating for each actor, depending on the roles they are fulfilling, their costs and benefits in a dynamic way.

First we presented a detailed analysis of all roles required to offer eCare services. Health care, eCare platform and finance providers form a complex eco-system compared to the current situation. We presented a realistic business model, where the home care provider takes up a dominant role in delivering eCare platforms and services towards the patients. The results show for the health care actors (general practitioners, home care and retirement homes), a social benefit, either in terms of new customers, time savings or serving the needs of customers. The largest 
components of the tariff paid by the patients include call center and network connectivity costs. The eCare infrastructure would ideally be subsidized by the government to enhance the speed-up of rollout of eCare services.

Finally concluding, all actors participating in the offering of the eCare platform and services can benefit from the implementation of the system, which is of great importance to help formulating a business model towards governmental agencies, insurance companies, health care providers or private investors as to how much and how soon to invest in eCare.

Future work includes the extension of the techno-economic and multi-actor analysis with more extended business models, depending on the eCare services offered and the country specific implications.

\section{Acknowledgements}

This research was carried out as part of the IBBT TranseCare project. This project is co-funded by IBBT, IWT and Televic, Androme, Custodix, SOL, WGK, In-HAM and UZGent. This work was carried out in the framework of the COST ISO605 Econ@Tel project. More information about smart care innovations and initiatives in Flanders can be found on http://www.smartcareplatform.eu/.

\section{References}

[1] European Commission (2010). "Business models for eHealth". Prepared for ICT for Health Unit, DG Information Society and Media, 28 February 2010, http://ec.europa.eu/information society/activities/health/docs/studies/business model/busin ess models eHealth report.pdf

[2] M. A. Hebert, B. Korabek (2004). "Stakeholder Readiness for Telehomecare: Implications for Implementation". Telemedicine Journal and e-Health. March 2004: 85-92

[3] M. E. Dávalos, M. T. French, A. E. Burdick, S. C. Simmons (2009). "Economic Evaluation of Telemedicine: Review of the Literature and Research Guidelines for Benefit-Cost Analysis". Telemedicine and e-Health, December 2009: 933-948

[4] S. V. Rojas, M.-P. Gagnon (2008). "A Systematic Review of the Key Indicators for Assessing Telehomecare Cost-Effectiveness". Telemedicine and e-Health, November 2008: 896-904.

[5] K. H. Dansky, L. Palmer, D. Shea, K. H. Bowles (2001). "Cost Analysis of Telehomecare". Telemedicine Journal and e-Health. September 2001: 225-232

[6] IBBT - Transecare project (https://projects.ibbt.be/transecare/)

[7] J. Van Ooteghem, S. De Maesschalck, K. Bamelis, J. Devos, P. Verhoeve, D. Colle, A. Ackaert, M. Pickavet, P. Demeester (2007). "An eHealth business model for independent living systems". Proceedings (on CD-ROM) of e-Challenges 2007, ISBN 978-1-58603801-4, The Hague, October 24-26, 2007

[8] J. Van Ooteghem, T. Tesch, S. Verbrugge, A. Ackaert, D. Colle, M. Pickavet, P. Demeester (2010). "Modeling Market Shares of Competing (e)Care Providers". Lecture Notes of the Institute for Computer Sciences, Social Informatics and Telecommunications Engineering, Volume 27, pp. 192-199, ISBN 978-3-642-11745-9, Published by Springer Berlin Heidelberg 